\title{
Полиморфные сайты в ITS-районах ядерных генов 35S pPHК у межвидовых гибридов Pulsatilla (Ranunculaceae)
}

\section{Polymorphic sites in ITS1-5.8S rDNA-ITS2 region of nuclear 35S rRNA genes in interspecies hybrids of Pulsatilla (Ranunculaceae)}

\author{
Пунина Е. О., Михайлова Ю. В., Шнеер В. С., Крапивская Е. Е., Родионов А. В. \\ Punina E. O., Mikhailova Ju. V., Shneyer V. S., Krapivskaya E. E., Rodionov A. V. \\ Ботанический институт им. В. Л. Комарова РАН, г. Санкт-Петербург, Россия._E-mail: elizaveta_punina@mail.ru, \\ mjulka@gmail.com,shneyer@rambler.ru
}

Komarov Botanical Institute of the Russian Academy of Sciences, Saint-Petersburg, Russia

\begin{abstract}
Peфepam. Исследовано распределение полиморфных сайтов (PS) в ITS-районах ядерных генов 35S pРНК у образцов из нескольких местонахождений трех видов рода Pulsatilla (P. patens, P. vernalis, P. pratensis) и их попарных межвидовых гибридов $(P . \times$ intermedia, $P . \times$ spuria, $P . \times$ wolfgangiana $)$. Количество и положение PS варьировало как внутри каждого вида и нотовида, так и между ними. Некоторые PS можно рассматривать как сохранившиеся свидетельства гибридизации, другие - как результат геномной нестабильности гибрида. В сети NeighbourNet большинство гибридов заняли промежуточное положение между видовыми кластерами. Положение образцов P. $\times$ intermedia внутри видовых кластеров $P$. patens может свидетельствовать об их интрогрессивной природе.
\end{abstract}

Ключевые слова. Межвидовая гибридизация, Pulsatilla, внутригеномный полиморфизм.

Summary. The distribution patterns of polymorphic sites (PS) in ITS1-5.8S rDNA-ITS2 region of nuclear 35S rRNA genes of three species of the genus Pulsatilla (P. patens, P. vernalis, P. pratensis) and their hybrids $(P . \times$ intermedia, $P . \times$ spuria, $P . \times$ wolfgangiana) in multiple samples from different locations were studied. The number and position of PS varied within each species and nothospecies as well as between them. Some PS can be considered as persistent evidence of past hybridization, whereas others as the result of genomic non-stability in a hybrid. Most of hybrid samples took intermediate place among clusters corresponding to species in NeighbourNet graph. The position of $P . \times$ intermedia samples within P. patens cluster can be evidence of their introgressive nature.

Key words. Interspecific hybridization, Pulsatilla, intragenomic polymorphism.

В молекулярной систематике растений сравнительный анализ ядерных последовательностей внутренних транскрибируемых спейсеров ITS1 и ITS2 рибосомальных генов 35S pPHК широко используется уже более четверти века. Принято считать, что, несмотря на многокопийность этих генов в геноме, их последовательности достаточно однородны, и как у аллополиплоидов, так и у межвидовых гибридов очень быстро происходит их изогенизация или же утрата копий одного из родителей (Kotseruba et al., 2003; Kovarik A. et al., 2008; Rodionov et al., 2017), поэтому при секвенировании ДНК мы обнаруживаем последовательность только одного из родительских видов. Однако имеются и примеры длительно существующего внутригеномного полиморфизма этих последовательностей. В этом случае при секвенировании по Сэнгеру на хроматограммах выявляются двойные пики, свидетельствующие о присутствии в геноме значительной доли иной последовательности ДНК. Самый яркий пример - это как дикорастущие, так и культивируемые пионы (Sang et al., 1995; Punina et al., 2012, 2017). У межвидовых гибридов пионов и видов гибридного происхождения в позициях нуклеотидов, по которым отличались виды-родители, почти всегда регистрируются полиморфные сайты (PS). Однако к настоящему времени стали накапливаться данные, согласно которым обнаружение PS при секвенировании необязательно свидетельствует об актах отдаленной гибридизации, сопровождавших образование вида или межвидового гибрида, но может отражать какие-то иные процессы эволюционных преобразований генома. Так, например, у тех же дикорастущих пионов было показано, что у Paeonia lactiflora Pall. - вида неги- 
бридного происхождения - регистрируется существенное количество PS, выявляемых как при секвенировании по Сэнгеру, так и при NGS (Illumina), что может может быть свидетельством активной внутривидовой дивергенции (Ефимов и др., 2017). Исследование некоторых аллополиплоидных злаков и дикорастущих межродовых гибридов из круга родства рода Elymus L. (пырейник) показало еще более сложную картину (Rodionov et al., 2018). В этом случае часть PS у гибридов соответствовала различающимся нуклеотидам в последовательностях предполагаемых родителей, часть не выявлялась в ожидаемых позициях, а часть, по-видимому, возникла de novo. Есть предположение, что внутригеномный полиморфизм, возникающий de novo, может быть свидетельством нестабильности композитного гибридного генома (Родионов и др., 2019).

В настоящей работе мы исследовали три вида и три нотовида рода Pulsatilla Mill., образованных при попарной гибридизации между исходными видами: P. patens (L.) Mill., P. vernalis (L.) Mill., $P$. pratensis (L.) Mill., $P . \times$ intermedia (Lasch) G. Don fil. $(P$. vernalis $\times P$. patens $), P . \times$ spuria Camus (P. vernalis $\times$ P. pratensis), и $P$. $\times$ wolfgangiana (Bess.) Juz. (P. patens $\times$ P. pratensis) из нескольких местонахождений на территории Ленинградской области в Лужском, Приозерском и Выборгском районах (20 образцов P. patens, $3-P$. vernalis, $6-P$. pratensis, $8-P$. $\times$ intermedia и по $2-P . \times$ spuria и $P . \times$ wolfgangiana). Все эти виды достаточно редки и нуждаются в охране, P. pratensis и $P$. vernalis занесены в Красную книгу Российской Федерации со статусом $3 б$ и $2 б$ (Гельтман, 2008), а P. patens - в Красную Книгу Ленинградской области (Гельтман, 2018).

Все родительские виды и нотовид $P$. $\times$ intermedia являются диплоидами с $2 n=16$ (Пунина, Гриф, 1984), хромосомные числа для $P . \times$ spuria и $P . \times$ wolfgangiana неизвестны, но можно предполагать, что они также диплоиды.

Примечательно то, что $P$. × intermedia - интрогрессивный гибрид, способный к возвратному скрещиванию с родительскими видами и демонстрирующий широкий спектр морфологической изменчивости, в то время как $P . \times$ spuria и $P . \times$ wolfgangiana, по-видимому, существуют только в виде стерильных особей первого поколения, и морфологической изменчивости у них мы не наблюдали (Пунина, Гриф, 1984; наши данные). В пользу этого свидетельствует проведенное нами исследование пыльцы при помощи кармин-теста. Так, у всех родительских видов доля выполненных и интенсивно окрашиваемых пыльцевых зерен составляла от 71 до $99 \%$, у $P$. $\times$ intermedia она сильно варьировала у разных особей от 1 до $93 \%$, у $P$. × spuria - от 1 до $18 \%$, и у $P$. × wolfgangiana - около $9 \%$. По морфологии все 3 родительских вида хорошо различаются между собой по комплексу морфологических и биологических признаков (цвет и размер листочков околоцветника, форма цветоноса, цвет опушения покрывала, форма листьев, зимование листьев и период их развития).

Небольшие фрагменты растений отбирались в силикагель, затем из собранного материала была выделена ДНК с помощью набора PlantMini Kit (Qiagen), амплифицированы ITS-районы с праймерами ITS-1р и ITS-4. Для ПЦР видов P. pratensis и P. patens была использована Таq-полимераза (СибЭнзим), тогда как амплифицировать ITS-районы у нотовидов и P. vernalis удалось только с помощью полимеразы Phire Hot Start II (набор Phire Plant Direct PCR Master Mix, Thermo Scientific). Секвенирование последовательностей ДНК проводили в ЦКП БИН РАН на генетическом анализаторе AbiPrism 3130 (Applied Biosystems). Полученные хроматограммы визуально проверялись на наличие полиморфных сайтов.

Анализ последовательностей ДНК выполняли с помощью программ MEGA 7.0 (Kumar et al., 2016), Chromas (http://technelysium.com.au/wp/chromas/).

Выявленные PS показаны в таблице. У P. patens у 20 разных образцов было выявлено от 1 до 5 PS, у 4-х образцов P. pratensis - от 0 до 2 PS, а у P. vernalis их оказалось несколько больше ожидаемого 2 у одного образца и 6 у двух других. В то же время у $P$. $\times$ intermedia количество PS также варьирует от 1 до 6 у 8 исследованных нами образцов, и только в четырех позициях эти PS соответствуют видоспецифичным заменам у родительских видов P. patens и P. vernalis, в отдельных случаях эти PS совпадают с таковыми у какого-либо из родительских видов, а в некоторых позициях такого соответствия нет. У $P . \times$ wolfgangiana можно отметить 6 PS, которые можно рассматривать как «следы гибридизации», а 1-2 - соответствуют PS у родительских видов. У P. × spuria наблюдается 3-4 PS, возникших в результате гибридизации, 2 - сооответствуют PS у P. vernalis, a 1 не соответствует ни сайту видоспецифичной замены, ни PS у родительских видов. 


\begin{tabular}{|c|c|c|c|c|c|c|c|c|c|c|c|c|c|c|c|c|c|c|c|c|c|c|c|c|c|c|c|c|c|c|c|}
\hline & 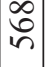 & $\mapsto$ & & & & & & & & & & & & & & & & & & & & $\lambda>$ & & & & & & 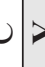 & & & \\
\hline & $\begin{array}{l}\infty \\
n \\
n\end{array}$ & 0 & $\lambda$ & & $\lambda$ & $\lambda$ & $\lambda$ & $\lambda$ & & $\lambda$ & & & & & & & & & & & & $H F$ & -1 & -6 & -6 & -6 & 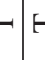 & & & $-1 \mathrm{H}$ & 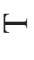 \\
\hline & $\begin{array}{l}n \\
n \\
n\end{array}$ & $\bullet$ & & & & & & & & & & & & & & & & & & & & & & & & & & & & & 0 \\
\hline & సे & $H$ & & 0 & & & $\lambda$ & $\lambda$ & $>$ & $\lambda$ & & $\lambda$ & & & & $>$ & 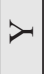 & 0 & 0 & $U$ & $>1$ & & & & & & & & & & \\
\hline 会 & 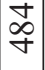 & $\mapsto$ & & & & & & & & & & & & & & & & & & & & 33 & $\geqslant$ & $\ll$ & & & $\varangle \mid$ & & & & \\
\hline & 号 & 0 & & & & & & & & & & & & & & & & & & & & $\succ>$ & $\succ$ & $\succ t$ & -1 & $>1$ & $\succ \mathrm{F}$ & $-\mathrm{f}$ & - & & $>$ \\
\hline & $\frac{\infty}{\sigma}$ & 0 & & & & & & & & & & & & & & & & & & & & $\lambda>$ & & $t h$ & 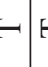 & & $-\mathrm{F}$ & $-1>$ & 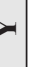 & & \\
\hline & $\begin{array}{c}\bar{\infty} \\
m\end{array}$ & 0 & & & & & & & & & $\forall$ & & $\checkmark$ & $\checkmark$ & & $\checkmark$ & & & & & & $\simeq 8$ & $\simeq$ & $\simeq$ & $\ll$ & $\ll$ & $\mathbb{4}$ & & & & \\
\hline & $\frac{\infty}{\infty}$ & $\varangle$ & $\simeq$ & ט & & $\simeq$ & & ט & $\simeq$ & $\simeq$ & $\simeq$ & $\simeq$ & $\simeq$ & $\simeq$ & $\simeq$ & $\simeq$ & $\simeq$ & 0 & $\simeq$ & $\simeq$ & $\simeq$ & & & & & & & & & 33 & 3 \\
\hline & 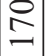 & $\varangle$ & & & & & & & & & & & & & & & & & & & & & & & & & $B$ & 3 & & 33 & 3 \\
\hline & $\Xi$ & $\varangle$ & & & $\Sigma$ & $\Sigma$ & $\Sigma$ & $\Sigma$ & $\Sigma$ & $\Sigma$ & & & & & & & & & & & & & & & & & & & & & $\Sigma$ \\
\hline & $\stackrel{t}{0}$ & 0 & & & & & & & & & & & & & & & & & & & & & & & & & & $\Rightarrow>$ & & & $\lambda$ \\
\hline & $\overline{0}$ & 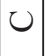 & 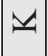 & $\triangle$ & $\Sigma$ & $\Sigma$ & $\Sigma$ & $\Sigma$ & $\Sigma$ & $\Sigma$ & & & & & & & & & & & & & & & & & & & & $\ll \mid<$ & $\ll$ \\
\hline[ & $\bar{a}$ & 0 & & & & & & & & & $\lambda$ & & $H$ & & & $\lambda$ & & & & & & $\lambda$ & & & & & & & & & \\
\hline & $\hat{6}$ & 0 & & & & $>$ & $>$ & & & & & & & & & $\lambda$ & $>$ & & & & & $\Sigma$ & $\Sigma$ & $\ll$ & $\ll$ & $\ll$ & 4 & $\sum$ & $\Sigma$ & & \\
\hline & 8 & $\varangle$ & & & & & & & & & & & & & & & & & & & & $\simeq$ & 幽 & ט & 0 & 0 & ט) & & & & \\
\hline & 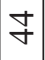 & 0 & & & & $\Sigma$ & & & & $\Sigma$ & & & & & & & & & & & & & & & & & & & & $\ll \mid<$ & $\ll$ \\
\hline & D & 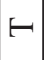 & & & & & & & 3 & & & & & & & & & & & & & & & & & & & & & & 3 \\
\hline & $\sim$ & 0 & & & & & & & & & & & & & & & & & & & & & & & & & 0 & $\cap 0$ & s & & \\
\hline & 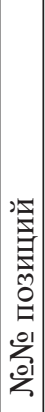 & $\begin{array}{l} \\
0 \\
\tilde{\vec{n}} \\
\overline{0} \\
0 \\
0 \\
0 \\
0\end{array}$ & 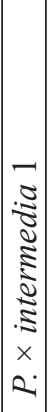 & 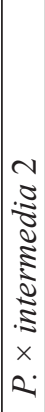 & 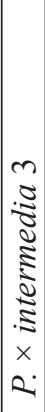 & 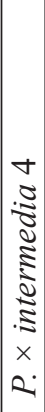 & 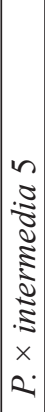 & 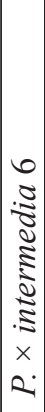 & 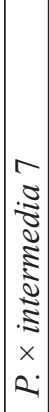 & 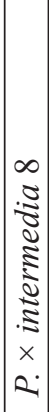 & 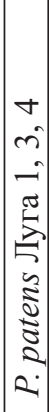 & 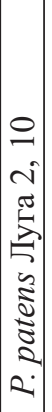 & 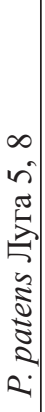 & 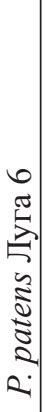 & 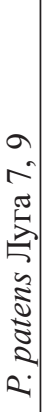 & 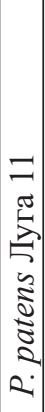 & 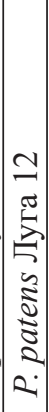 & 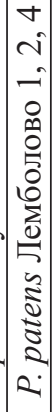 & 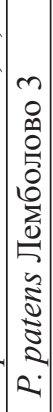 & 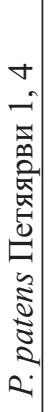 & 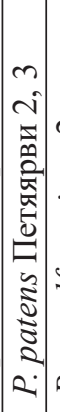 & 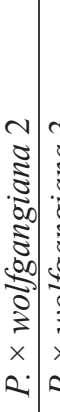 & 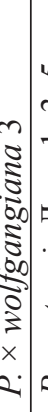 & 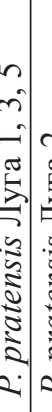 & 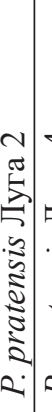 & 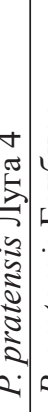 & 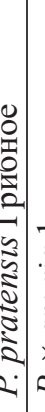 & 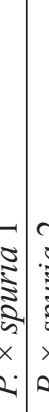 & 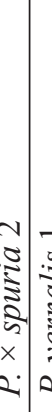 & 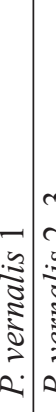 & \\
\hline
\end{tabular}


Таким образом, можно сделать вывод о том, что у видов и нотовидов Pulsatilla наблюдается индивидуально различная степень внутригеномного полиморфизма, причем у нотовидов этот внутригеномный полиморфизм возникает не только как следствие межвидовой гибридизации и сохранения в геноме обоих пулов родительских последовательностей, но и в силу каких-то иных причин, в том числе, вероятно, и как результат геномной нестабильности гибрида.

Для определения степени сходства исследованных нами видов и нотовидов мы построили сеть NeighbourNet в программе Splitstree4 (Huson, Bryant, 2006) (рисунок). В результате пул последовательностей ITS распределился по отдельным кластерам, соответствующим диплоидным видам. В кластер P. pratensis попали образцы как с Карельского перешейка (дер. Грибное), так и из окрестностей г. Луги. Собственный компактный кластер образовали представители P. vernalis. Кластер P. patens оказался более «рыхлым», т. е. этот вид, вероятно, генетически менее однороден, чем два других диплоида. В кластере P. patens можно выделить подкластер, включающий только лужские экземпляры, и подкластер как с лужскими, так и с экземплярами с Карельского перешейка (окр. пос. Лемболово и Петяярви). Интересно распределяются гибриды в сети. $P . \times$ spuria $(P$. vernalis $\times$ P. pratensis) занимает промежуточное положение на ветви, ведущей к кластеру pratensis от общего «ствола», но ближе к pratensis. Два образца $P$. $\times$ wolfgangiana $(P$. patens $\times$ P. pratensis) занимают положение на этой ветви ближе к «стволу», от которого расходятся остальные кластеры, и ближе к P. patens. Наконец, 6 образцов P. $\times$ intermedia (P. patens $\times$ P. vernalis) заняли положение на «стволе», от которого отходят остальные кластеры, т. е. промежуточное положением между $P$. patens и остальными образцами; а два образца $P$. $\times$ intermedia оказались в кластере с P. patens смешанного географического происхождения. Таким образом, большинство гибридов занимают промежуточное положение между видовыми кластерами. Положение двух гибридных образцов $P . \times$ intermedia внутри видовых кластеров $P$. patens, по нашему мнению, свидетельствует об их интрогрессивной природе.

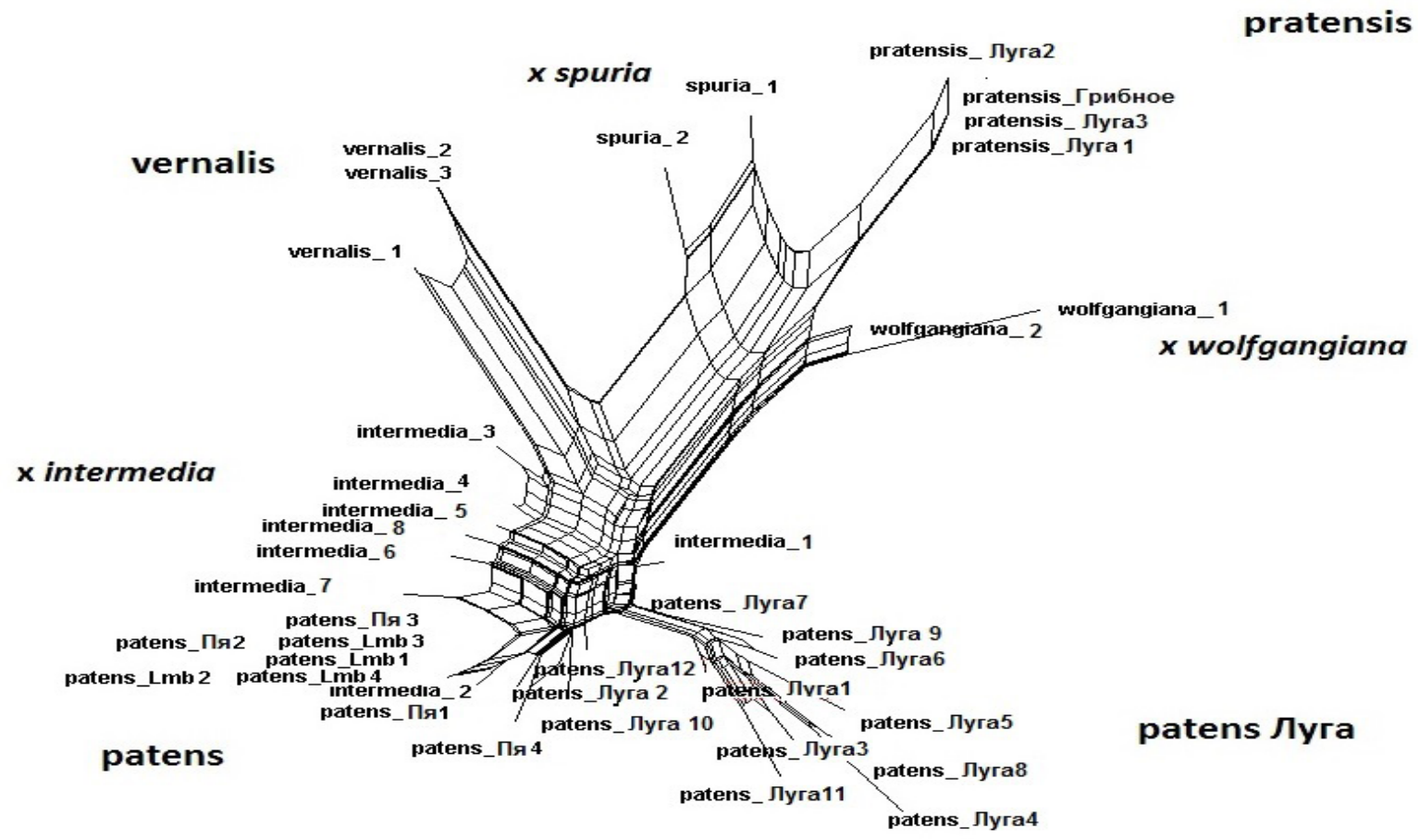

Рис. Сеть NeighbourNet, иллюстрирующая степень сходства и различий ITS-последовательностей исследованных видов и нотовидов Pulsatilla.

Работа выполнена на оборудовании ЦКП «Клеточные и молекулярные технологии изучения растений и грибов» при поддержке гранта РФФИ № 18-04-01040 и частично Программы Президиума РАН «Биоразнообразие природных систем» (проект № 0126-2018-0029). Авторы благодарят Ю. М. Пунина и М. В. Цепакину за помощь в сборе материала. 


\section{ЛИТЕРАТУРА}

Гельтман Д. В. Pulsatilla pratensis. P. vernalis - Красная книга Российской Федерации (растения и грибы). М.: Товарищество научных изданий КМК, 2008. - С. 483-485.

Гельтман Д. В. Pulsatilla patens, P. pratensis. P. vernalis // Красная книга Ленинградской области. Объекты растительного мира. - СПб.: Марафон, 2018. - С. 229-230, 762-764.

Ефимов С. В., Дегтярева Г. В., Терентьева Е. И. и др. Изучение полиморфизма ампликонов ITS1 и ITS2 ядерной рибосомальной ДНК с помощью высокопроизводительного параллельного секвенирования и прямого секвенирования по Сэнгеру у Paeonia lactiflora (Paeoniaceae) // Проблемы ботаники Южной Сибири и Монголии, 2017. - № 16. - C. 246-249.

Пунина Е. О., Гриф В. Г. Кариосистематическое исследование видов и естественных гибридов рода Pulsatilla (Ranunculaceae) в Ленинградской области // Бот. журн., 1984. - Т. 69, № 12. - С. 1673-1678.

Родионов A. В., Амосова A. В., Беляков $\boldsymbol{E}$. $\boldsymbol{A}$. и др. Генетические последствия межвидовой гибридизации, ее роль в видообразовании и фенотипическом разнообразии растений // Генетика, 2019. - Т. 55, № 3. - С. 255-272.

Huson D. H., Bryant D. Application of phylogenetic networks in evolutionary studies // Mol. Biol. Evol., 2006. - V. 23, № 2. - P. 254-267.

Kotseruba V., Gernand D., Meister A. et al. Uniparental loss of ribosomal DNA in the allotetraploid grass Zingeria trichopoda $(2 n=8) / /$ Genome., 2003. - V. 46. - P. 156-163.

Kovarik A., Dadejova M., Lim Y. K. et al. Evolution of rDNA in Nicotiana allopolyploids: A potential link between rDNA homogenization and epigenetics // Ann. Bot., 2008. - V. 101. - P. 815-823.

Kumar S., Stecher G., Tamura K. MEGA7: Molecular Evolutionary Genetics Analysis version 7.0 for bigger datasets // Mol. Biol. Evol., 2016. - V. 33, № 7. - P. 1870-1874.

Punina E. O., Machs E. M., Krapivskaya E. E. et al. Interspecific hybridization in the genus Paeonia (Paeoniaceae): polymorphic sites in transcribed spacers of the 45S rRNA genes as indicators of natural and artificial peony hybrids // Russ. J. of Genetics, 2012. - V. 48, № 7. - C. 684-697.

Punina E. O., Machs E. M., Krapivskaya E. E. et al. Polymorphic sites in transcribed spacers of $35 \mathrm{~s}$ rRNA genes as an indicator of origin of the paeonia cultivars // Russ. J. of Genetics, 2017. - V. 53, № 2. - C. $202-212$.

Rodionov A. V., Gnutikov A. A., Kotsinyan A. R., Kotseruba V. V., Nosov N. N., Punina E. O., Rayko M. P., Tyupa N. B., Kim E. S. ITS1-5.8S rDNA-ITS2 sequence in 35S rRNA genes as marker during reconstruction of phylogeny of cereals (Poaceae family) // Biology Bulletin Reviews, 2017. - V. 7. - № 2. - C. 85-102.

Rodionov A. V., Dobryakova K. S., Punina E. O. Polymorphic sites in ITS1-5.8S rDNA-ITS2 region in hybridogenic genus $\times$ Elyhordeum and putative interspecific hybrids Elymus (Poaceae: Triticeae) // Russ. J. of Genetics, 2018. -V. 54, № 9. - C. 1025-1039.

Sang T., Crawford D. J., Stuessy T. F. Documentation of reticulate evolution in peonies (Paeonia) using internal transcribed spacer sequences of nuclear ribosomal DNA: implications for biogeography and concerted evolution // Proc. Natl Acad. Sci. USA., 1995. - V. 92. - P. 6813-6817. 